\title{
Patogenia da asma
}

\author{
The pathogenesis of asthma
}

\author{
Eduardo Costa F. Silva* \\ Gabriela A. C. Dias
}

\section{Resumo}

A asma é uma doença inflamatória crônica caracterizada por hiper-responsividade das vias aéreas e que se manifesta por obstrução ao fluxo aéreo, reversível espontaneamente ou pelo tratamento. Seu desenvolvimento depende da interação entre fatores externos e predisposição genética ao desenvolvimento de hiper-responsividade brônquica e atopia. As crises asmáticas são desencadeadas por fatores específicos ou alérgicos (alérgenos inaláveis, substâncias derivadas de ácaros, animais domésticos, baratas e fungos do ar) e inespecíficos (infecções virais, tabaco, mudanças climáticas e medicamentos). A inflamação brônquica constitui o mais importante mecanismo fisiopatológico da asma e resulta de interações complexas entre células inflamatórias, citocinas, mediadores e células estruturais das vias aéreas. Algumas condições clínicas podem estar associadas com a asma e contribuir para seu agravamento, tais como a rinossinusopatia, a doença do refluxo gastroesofágico e as micoses broncopulmonares alérgicas.

Descritores: Asma; Inflamação; Etiologia.

\begin{abstract}
Asthma is a chronic inflammatory disease which is characterized by airway hyperresponsiveness with reversible bronchial obstruction, spontaneously or with treatment. Its development depends on interactions between external factors and genetic predisposition to atopy and bronchial hyperresponsiveness. Exacerbations are caused by allergens (antigens from dust mites, pets, cockroach and molds), viral infections and other irritants (tobacco, weather changes and medications). Bronchial inflammation is the major feature in asthma pathogenesis and results from complex interactions between inflammatory cells, structural bronchial cells, cytokines and inflammatory mediators. Some clinical comorbidities can be associated with asthma, contributing to its severity, such as rhinosinusitis, gastroesophageal reflux and broncopulmonary allergic fungal diseases.
\end{abstract}

Keywords: Asthma; Inflammation; Etiology. 


\section{Imunopatogenia da asma}

O desenvolvimento da asma brônquica está associado a vários fatores externos (ambientais e ocupacionais) e individuais (genéticos e psicossociais), e depende da interação entre estes fatores externos e a predisposição genética ao desenvolvimento de hiper-responsividade brônquica e atopia, ou seja, predisposição genética para a produção exagerada de $\operatorname{IgE}$ específica para antígenos habituais do meio ambiente.

Os principais fatores externos associados ao desenvolvimento de asma são os alérgenos inaláveis (substâncias do corpo e fezes de ácaros domésticos, antígenos fúngicos, de insetos como baratas e de animais domésticos, além de pólens) e os vírus respiratórios, particularmente as infecções pelo vírus sincicial respiratório (VSR) nos primeiros anos de vida. Poluentes ambientais, como a fumaça de cigarro, gases e poluentes particulados em suspensão no ar, como as partículas provenientes da combustão do óleo diesel, também parecem atuar como fatores promotores ou facilitadores da sensibilização aos alérgenos e da hiper-responsividade brônquica em indivíduos predispostos. ${ }^{1,2}$

Em relação aos agentes ocupacionais, cerca de 300 substâncias já foram identificadas como potenciais agentes causais de asma ocupacional, e acredita-se que $10 \%$ das asmas iniciadas na idade adulta estejam associadas a estes agentes. ${ }^{2}$ $\mathrm{Na}$ asma ocupacional estão bem definidos agentes ocupacionais que induzem asma através de mecanismo alérgico (IgE mediado) e outros que induzem asma não alérgica. Eles são divididos em alto (>10 kd) e baixo peso molecular. Os primeiros são proteínas de origem animal e vegetal, cujos principais exemplos são os cereais, que causam asma no padeiro; látex, nos profissionais de saúde; epitélio, saliva e urina de animais, nos veterinários e trabalhadores de laboratório. $\mathrm{O}$ segundo grupo engloba as substâncias químicas como isocianatos (trabalhadores da indústria de plásticos e borracha) e ácidos anidridos (trabalhadores da indústria de resina epóxi, plásticos e inseticidas). ${ }^{3}$
Diversos genes candidatos, em diferentes níveis de associação e penetração, têm sido associados a diferentes fenótipos de asma. Tipicamente, o impacto destes diversos genes, em especial nas manifestações fenotípicas da doença, é pequeno. Entretanto, grandes efeitos podem advir da atuação sinérgica de múltiplos destes genes, em um contexto ambiental favorável. A grande heterogeneidade fenotípica da asma, que pode iniciar em qualquer idade, pode ser intermitente e leve, até mesmo transitória, ou, ao contrário, persistente e extremamente grave, além de estar associada a diferentes fenótipos intermediários, como atopia, hiper-responsividade brônquica, níveis séricos de IgE, dermatite atópica, dentre outros, colabora para a dificuldade na caracterização do papel específico de genes isolados no desenvolvimento da doença.

Mais de 30 genes já foram identificados como candidatos a susceptibilidade no desenvolvimento de asma e estão divididos em quatro grandes grupos: (a) associados a imunidade inata e imunorregulação (p. ex. CD14, TLR2, 4, 6, 10, IL-10, TGF-beta e HLA DR, DQ e DP); (b) associados a atopia, diferenciação Th2 e suas funções (p. ex. GATA-3, IL-4, IL-4R, FcRI, IL-5, IL-5R e STAT-6); (c) associados a biologia epitelial e imunidade das mucosas (p. ex. genes de quimiocinas CCL5/RANTES, CCL11, CCL24, CCL26, filagrina e outros) e (d) associados a função pulmonar e remodelamento brônquico (ADAM-33, DPP-10 e HLA-G, dentre outros). ${ }^{4}$

Os efeitos da exposição fetal e nos primeiros anos de vida ao tabagismo materno, doenças infecciosas, dieta, aleitamento materno e infantil sobre o risco da asma podem ser modificados por suscetibilidade genética. Estudos epigenéticos recentes sugerem que genes relacionados à asma [glutathione S-transferase (GST), methylenetetrahydrofolate reductase (MTHFR), gasdermin-like (GSDML) e ORMDL3] podem ter sua expressão modificada por exposições ambientais, incluindo o tabaco. A asma de início precoce tem risco aumentado quando associado com a exposição ao tabaco na primeira infância, devido à variações genéticas dos genes 
ORDML3, GSDML, dentre outros. Além disso, a exposição ao tabaco na vida fetal parece estar associada com sibilância transitória na infância devido a alterações nos genes GST. ${ }^{5}$

Outras características individuais também estão associadas ao desenvolvimento de asma. Crianças do sexo masculino têm risco duas vezes superior em comparação com meninas da mesma idade, assim como a obesidade tem sido associada ao maior risco de desenvolver a doença. $^{2}$

A inflamação brônquica constitui o mais importante mecanismo fisiopatológico da asma e resulta de interações complexas entre células inflamatórias, mediadores e células estruturais das vias aéreas. Está presente não apenas em asmáticos graves ou com doença de longa duração, mas também em pacientes com asma de início recente, em pacientes com formas leves $\mathrm{da}$ doença e mesmo nos assintomáticos. A mucosa brônquica inflamada torna-se hiper-reativa a diversos estímulos, sejam eles alérgicos ou não.

$\mathrm{Na}$ asma alérgica, que representa a maioria dos casos, a resposta mediada por IgE causa alterações imediatas, minutos após a exposição ao(s) alérgeno(s), e alterações tardias, que representarão a resposta inflamatória crônica característica da doença (figura 1).

Os indivíduos atópicos - que têm a predisposição geneticamente determinada para produzirem grandes quantidades de anticorpos IgE específicos para alérgenos ambientais/inaláveis (substâncias de ácaros da poeira, fungos, insetos, animais domésticos e pólens) -, após estarem sensibilizados, ou seja, já produzirem IgE específica para um ou mais destes alérgenos, apresentam uma resposta de hipersensibilidade imediata (mediada por IgE) na mucosa da via aérea quando inalam essas substâncias. A ligação do alérgeno com a IgE na membrana dos

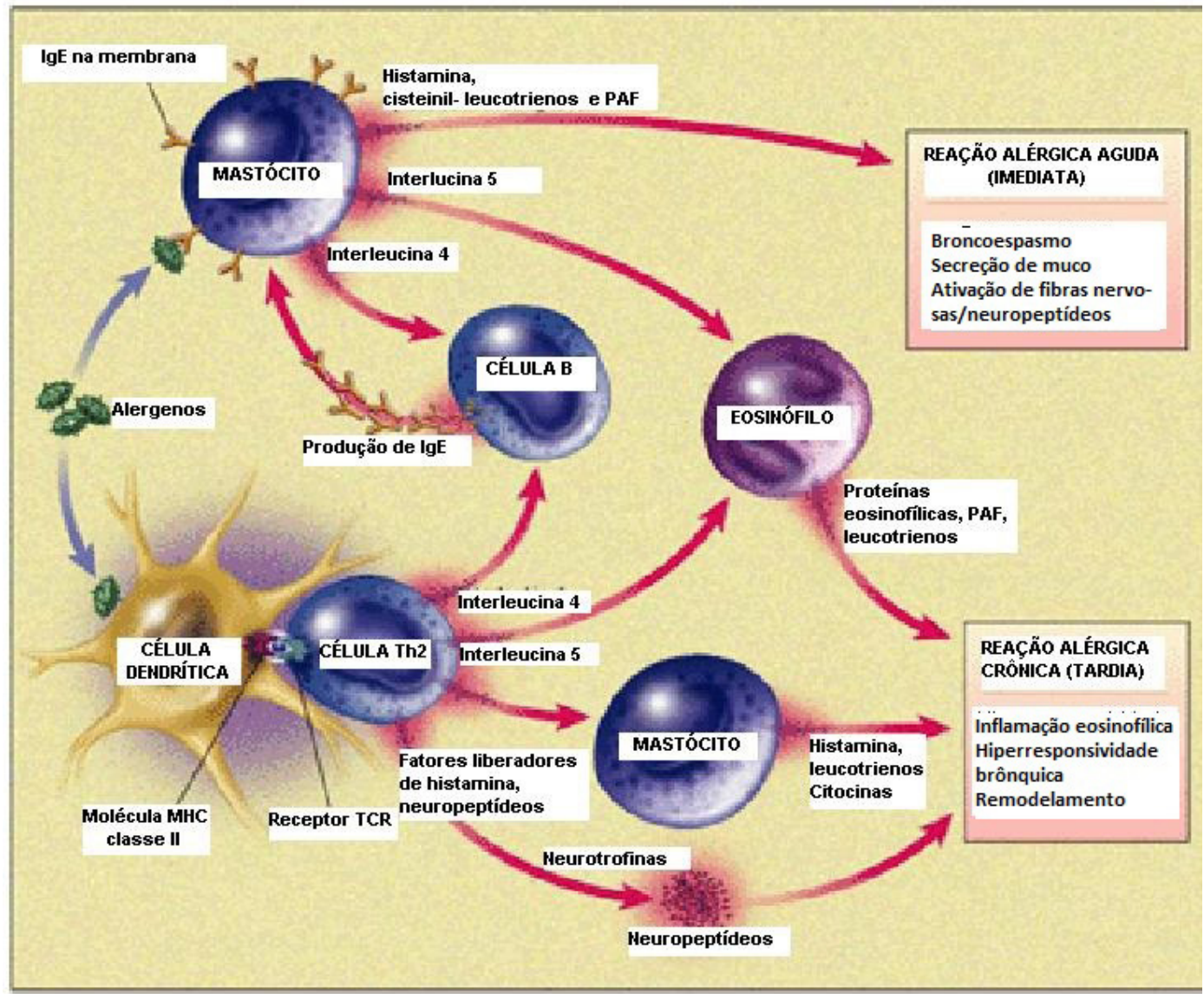

Figura 1: Fases e células da resposta mediada por IgE.

Fonte: New Eng J Med (adaptado). 
mastócitos na mucosa e submucosa brônquicas leva à ativação e desgranulação destas células, que liberam mediadores inflamatórios pré-formados (já estocados em seus grânulos), como a histamina e o fator ativador de plaquetas (PAF), e mediadores neoformados, produzidos a partir do ácido aracdônico liberado das membranas celulares, como prostaglandinas e leucotrienos. Os efeitos imediatos destas substâncias são vasodilatação e extravasamento vascular, com consequente edema da parede brônquica, hipersecreção de muco e broncoconstrição, responsáveis pelas manifestações clínicas da crise de asma (dispnéia, tosse com secreção viscosa, sibilos e sensação de aperto no peito). ${ }^{1,2}$

Os mastócitos ativados também produzem interleucinas (IL-3, IL-5), fator estimulador de crescimento de granulócitos e monócitos (GM-CSF), que, junto com os leucotrienos, ativam e atraem outras células inflamatórias à parede brônquica, perpetuando o processo inflamatório local. A inflamação brônquica da asma possui características especiais, além da ativação e desgranulação de mastócitos, como infiltração eosinofílica, lesão intersticial e epitelial das vias aéreas e ativação de linfócitos Th2, que produzem citocinas (como IL-4, IL-5, IL-13, entre outras) responsáveis pela amplificação e agravamento do processo inflamatório e estímulo continuado à produção de mais IgE específica aos alérgenos ambientais.

A IL-4 tem papel importante no aumento tanto da produção de IgE específica como da expressão de receptores de alta e baixa afinidade para IgE por muitas células inflamatórias, como mastócitos, basófilos e eosinófilos. A IL-5 é importante na atração, ativação e aumento da sobrevida do eosinófilo - principal célula efetora da lesão tecidual -, através da liberação de proteínas catiônicas, que agridem a matriz extracelular e as células epiteliais. A IL-13 age de forma sinérgica com a IL-4, aumentando a produção de IgE específica por linfócitos $\mathrm{B}$ diferenciados em plasmócitos, tanto em nível local como a distância.

A ERK1 (extracelular signal-regulated ki- nase) é uma proteína de sinalização que regula a meiose e mitose de células diferenciadas, inclusive linfócitos $\mathrm{T}$ e atua também em vários processos celulares, como crescimento, proliferação, diferenciação e secreção de citocinas, além de ter papel importante na diferenciação dos linfócitos Th2 e desenvolvimento da asma brônquica em modelos experimentais. ${ }^{6}$

Vários mediadores inflamatórios e citocinas também são liberados por outras células ativadas, como macrófagos (fator de necrose tumoral - TNF- $\alpha$-, IL-6, óxido nítrico), pelos linfócitos T (IL-2, IL-3, IL-4, IL-5 e GM-CSF), pelos eosinófilos (proteína básica principal MBP -, proteína catiônica eosinofílica - ECP -, peroxidase eosinofílica - EPO -, PGs, LTs e citocinas), pelos neutrófilos (elastase) e pelas células epiteliais (endotelina-1, LTs, PGs, óxido nítrico). Além disso, o endotélio vascular ativado tem um papel importante no recrutamento de células inflamatórias através do aumento da expressão de moléculas de adesão, como ICAM-1 e VCAM-1.,2,7

Através de seus mediadores, as células causam lesões e alterações na integridade epitelial, anormalidades no controle neural autonômico e no tônus da via aérea, alterações na permeabilidade vascular, hipersecreção de muco, mudanças na função mucociliar e aumento da reatividade do músculo liso da via aérea, levando à hiper-responsividade brônquica. ${ }^{7,8}$

A asma é considerada uma doença inflamatória das vias aéreas mediada por linfócitos Th-2 com eosinofilia tecidual, remodelamento e obstrução brônquica. Outros fenótipos de células T, incluindo células Th-17 e NK-T, também contribuem na patogênese da asma.

As células Th17 diferenciam-se para produzir grandes quantidades de IL-17 (uma quimiocina para neutrófilos), que pode ser importante na asma com fenótipo de inflamação neutrofílica. As células NK-T têm um papel crucial na patogênese da exacerbação da asma em modelos animais. Koh et al. demonstraram que os níveis séricos destas células estão diminuídos durante a exacerbação da asma secundária à infecção viral, 
sugerindo que elas foram mobilizadas para vias aéreas e pulmões durante esses episódios. ${ }^{9,10,11}$

Neste processo inflamatório crônico, as células epiteliais e miofi-broblastos, presentes abaixo do epitélio, ativam e proliferam-se iniciando a deposição intersticial de colágeno e proteoglicanos na lâmina reticular da membrana basal, o que explica o seu aparente espessamento e as lesões irreversíveis que podem ocorrer em pacientes com asma mais grave ou de longa evolução. Outras alterações, incluindo hipertrofia e hiperplasia do músculo liso, elevação no número de células caliciformes, aumento das glândulas e vasos sanguíneos submucosos e alteração no depósito/degradação dos componentes da matriz extracelular, são constituintes do remodelamento que interfere na arquitetura da via aérea, podendo levar à irreversibilidade da obstrução brônquica nos casos graves e de longa evolução.

Todas estas alterações estruturais ocorrem devido à ativação e desregulação da atividade normal da chamada unidade trófica epitéliomesenquimal, representada pelo epitélio brônquico, os miofibroblastos da camada subepitelial e o músculo liso brônquico. Estudos recentes, inclusive, demonstraram a capacidade da célula muscular lisa ativada em se transformar também numa célula com atividade pró-inflamatória, produzindo citocinas e adquirindo a capacidade de expressar diversas moléculas de superfície importantes na inflamação crônica. ${ }^{7,8}$

Infecções virais do trato respiratório alto ou baixo são o principal fator desencadeante de crises, tanto em adultos quanto em crianças. Os vírus respiratórios têm a capacidade de aumentar consideravelmente a hiper-responsividade brônquica, ao estimularem o processo inflamatório e aumentarem a disfunção autonômica local, com aumento significativo da produção de neuropeptídeos (substância $\mathrm{P}$, neurocininas A e $B$ etc.) pelas fibras nervosas não adrenérgicas/ não colinérgicas (NANC) da submucosa. Além disso, o atópico apresenta maior facilidade em contrair infecções virais respiratórias, particu- larmente pelo rinovírus, que utiliza moléculas de adesão (como a ICAM-1), que, por sua vez, têm sua expressão aumentada no epitélio brônquico inflamado, como receptores oportunos para a infecção destas células. Desta forma, os vírus podem ser importantes fatores de aumento e manutenção da inflamação brônquica e de agravamento da doença, sobretudo em crianças. ${ }^{12}$

Alterações anatomopatológicas, anteriormente identificadas apenas em casos graves de morte por asma, atualmente são encontradas mesmo em indivíduos com formas leves da doença e até mesmo em crianças, graças aos métodos disponíveis de estudo e obtenção de biópsias brônquicas.

A fibrose subepitelial está presente, em graus variáveis, em todos os indivíduos com asma, mesmo antes do surgimento de sintomas. Há hipertrofia e hiperplasia da musculatura lisa brônquica, que se correlaciona com a gravidade e o tempo de doença. Estas alterações, associadas à proliferação vascular e ao aumento de tamanho das glândulas submucosas, colaboram para o progressivo espessamento da parede brônquica, denominado remodelamento brônquico, e redução da reversibilidade da obstrução ao fluxo aéreo. ${ }^{2,7,8}$

Com a progressão do processo inflamatório e a consequente lesão ao epitélio brônquico, ocorre destacamento de áreas de células epiteliais contíguas e maior exposição de terminações nervosas sensitivas a agentes irritantes, bem como de células inflamatórias a alérgenos. Em casos de morte por asma, observa-se grande quantidade de muco rico em eosinófilos na luz brônquica, cristais de Charcot-Layden (agregados de proteínas catiônicas eosinofílicas), espirais de Curchmann (aglomerados de eosinófilos moldados), extensa lesão epitelial, intenso infiltrado de linfócitos e eosinófilos na submucosa, além de exagerado aumento da musculatura lisa brônquica, de glândulas da submucosa brônquica e extensa fibrose com espessamento subepitelial, ou seja, extenso remodelamento da via aérea inferior (figura 2). 

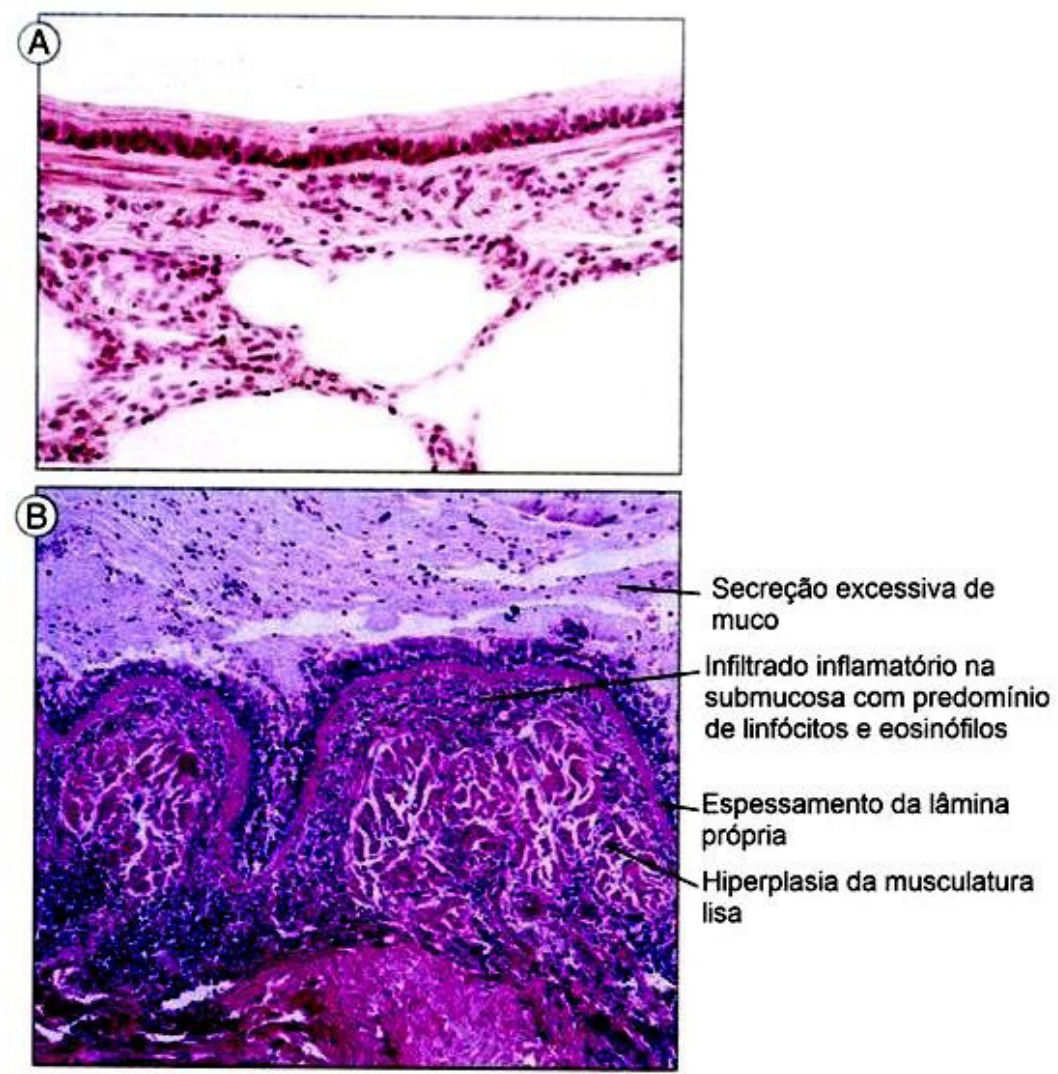

Figura 2: Histopatologia do brônquio normal (A) e brônquio na asma fatal (B). Fonte: ABBAS - Cellular and molecular immunology.

\section{Fatores desencadeantes de}

\section{crises de asma}

A hiper-responsividade brônquica característica da asma é ampla, fazendo com que o paciente asmático esteja sujeito ao desencadeamento de crises por diversos fatores, específicos (alérgicos) e inespecíficos (não alérgicos).

Dentre os específicos destacam-se os alérgenos inaláveis, substâncias derivadas de ácaros domésticos e animais - como cães e gatos, baratas e fungos do ar. Na região Sul do Brasil, assim como no Hemisfério Norte, onde as estações climáticas são mais bem-definidas, os polens também são importantes desencadeantes de sintomas já que ocorre polinização em determinadas épocas do ano. No Rio de Janeiro, no entanto, estes alérgenos não são desencadeantes de sintomas, apesar de encontrarmos indivíduos sensibilizados a eles nesta região.

Os fatores inespecíficos incluem as infecções virais (rinovírus, vírus sincicial respirató- rio, adenovírus, influenza e parainfluenza), que são a causa mais frequente de crises de asma em lactentes e crianças (até 90\% das crises). Em adultos cerca de $40 \%$ das crises de asma estão associadas à infecção viral, enquanto que cerca de $10 \%$ podem estar associadas à infecção bacteriana subclínica. ${ }^{12}$

As infecções virais e alérgenos interagem, aumentando o risco das exacerbações. O rinovírus é o vírus detectado com maior frequência, exceto em lactentes hospitalizados devido à bronquiolite, nos quais o vírus sincicial respiratório (VSR) é o principal responsável. A gripe é uma infecção comum durante o inverno. Após a pandemia da influenza A (H1N1), em 2009, vários estudos destacaram a asma como comorbidade importante nesta infecção, cujos marcadores de gravidade, como internação, admissão em unidade de terapia intensiva e mortalidade foram associados com o diagnóstico de asma. ${ }^{13}$

Outros desencadeantes inespecíficos são as mudanças climáticas, o ar frio e seco, os po- 
luentes ambientais, inclusive o tabaco e odores fortes (detergentes, perfumes, tintas).

O tabagismo induz um padrão de inflamação não eosinofílica com resistência relativa aos corticosteroides. Os atendimentos em emergência e internações hospitalares de adultos asmáticos fumantes são mais frequentes em comparação aos asmáticos não fumantes. Há evidências de que o tabagismo é um fator de risco para asma quase fatal e fatal. ${ }^{2,7,13}$

O exercício físico desencadeia crises de asma, muitas vezes manifestadas apenas por tosse seca e baixa tolerância ao esforço, principalmente em crianças e adolescentes. Nesses casos, os mastócitos são ativados diretamente pelo resfriamento e aumento de osmolaridade na via aérea, secundários à hiperventilação do esforço físico. Estas alterações também podem acontecer eventualmente durante o riso. ${ }^{14,15}$

Cerca de $10 \%$ dos asmáticos apresentam sensibilidade ao ácido acetil-salicílico (AAS) e a anti-inflamatórios não hormonais (AINHs), que podem desencadear crises se usados por via sistêmica ou mesmo tópica. Alguns desses pacientes evoluem com asma grave, primariamente não alérgica, associada com rinossinusite e polipose nasal (atualmente chamada doença respiratória exacerbada pela aspirina - DREA -, ou síndrome de Samter). Na DREA, o bloqueio das cicloxigenases (principalmente COX-1) pela ação do AAS ou AINHs, com consequente aumento da produção de cisteinil-leucotrienos pela via da lipoxigenase, além de maior expressão de receptores para leucotrienos em células-alvo e redução dos efeitos moduladores da inflamação pela prostaglandina E2 e lipoxinas são os principais mecanismos responsáveis pelo desenvolvimento da doença respiratória. A asma tende a ter evolução grave, com crises igualmente graves e necessidade eventual de tratamento intensivo. A doença das vias aéreas, nesses casos, evolui mesmo após a suspensão do uso de AAS ou AINHs. ${ }^{1,2,8,16}$

Ocasionalmente alimentos podem desencadear crise de asma isolada. Em quadros de alergia alimentar o broncoespasmo pode ocorrer associado a outras manifestações de anafilaxia, como urticária, angioedema e hipotensão arterial.

Os betabloqueadores podem desencadear broncoespasmo em pacientes com hiper-responsividade brônquica subclínica, ou ainda agravar a asma pré-existente e, por isso, são contraindicados nesses pacientes. Os inibidores da enzima conversora da angiotensina (ECA), ao reduzirem a atividade de cininase, podem colaborar para a perda de controle da asma, mas raramente são causa isolada de broncoespasmo.

As exacerbações ocorrem em aproximadamente $20 \%$ das grávidas asmáticas. Elas podem ocorrer durante toda a gravidez; porém são mais frequentes no final do segundo trimestre. Os principais fatores de risco são a asma grave, as infecções virais e a interrupção do tratamento adequado devido à crença de que o tratamento prejudicaria o feto. ${ }^{13}$

Na prática clínica, nunca se deve menosprezar a influência de fatores emocionais sobre as doenças crônicas, e não é raro observar sua ação como desencadeante ou, pelo menos em parte, como agravante de crises de asma.

\section{Condições agravantes da evolução da asma}

Algumas condições clínicas podem estar associadas com a asma, e contribuir para seu agravamento, aumentando a necessidade do uso de medicamentos. São elas: a rinossinusopatia (aguda ou crônica), a doença do refluxo gastroesofágico (DRGE) e as micoses broncopulmonares alérgicas. Devem ser investigadas e tratadas quando houver sinais/sintomas de suspeição, ou quando a asma não responde ao tratamento de manutenção corretamente instituído. Entretanto, antes disso, deve-se ter em mente que a asma é uma enfermidade de etiopatogenia complexa, influenciada por diversos fatores externos e a adesão às diversas medidas terapêuticas para asma é difícil, devendo ser reavaliada em todo paciente que não esteja obtendo a resposta esperada ao tratamento. 


\section{Rinossinusite}

Estudos epidemiológicos e a própria prática clínica chamam a atenção para a associação importante entre rinite-sinusite-asma. Até $80 \%$ dos asmáticos em nosso meio têm rinite alérgica associada, que pode estar associada à sinusite alérgica crônica e é fator predisponente para a sinusopatia infecciosa. Por outro lado, cerca de $40 \%$ dos indivíduos com rinite alérgica têm algum grau de hiper-responsividade brônquica, muitas vezes subclínica, ou até mesmo asma. ${ }^{2,17}$

Os mesmos fatores genéticos e ambientais conhecidos, predisponentes e/ou desencadeantes de sintomas, atuam de forma similar na via aérea superior e inferior, levando à manifestações clínicas de rinite e asma alérgicas, respectivamente. Além disso, mesmo em fenótipos de asma não atópica (como a asma ou doença respiratória induzida/exacerbada pela aspirina), coexistem a inflamação nasossinusal, com polipose e asma, geralmente de evolução grave. As vias aéreas superiores e inferiores apresentam várias características anatômicas similares como as células epiteliais que revestem a mucosa, a lâmina própria e a matriz extracelular submucosa povoada por células com potencial imunoinflamatório - e poucas diferenças que residem, basicamente, na presença do grande plexo venoso da submucosa nasal (ausente na submucosa brônquica) e, de maneira inversa, na presença de miofibroblastos na submucosa brônquica e musculatura lisa envolvendo a árvore brônquica. ${ }^{17}$

Estudos demonstram que a presença de sinusopatia piora a evolução clínica de asma e está associada à maior frequência de asma grave. Além disso, o tratamento seja da rinite alérgica isolada, seja da rinossinusopatia alérgica ou infecciosa, melhora o controle da asma e reduz a hiper-responsividade brônquica. ${ }^{17-19}$ Mais de 1/3 dos pacientes com rinossinusopatia crônica e polipose nasal tem hiper-responsividade brônquica (com ou sem história de sibilância). ${ }^{20}$

Acredita-se que reflexos vagais (colinérgicos) nasossino-brônquicos, microaspirações repetidas - seja de agentes infecciosos ou de mediadores inflamatórios - e a maior produção de mediadores inflamatórios nas vias aéreas superiores, levando a efeitos a distância, contribuam para essa estreita associação entre rinossinusite e asma. ${ }^{18,19}$

\section{Refluxo gastroesofágico}

O refluxo gastroesofágico piora a asma, principalmente nos extremos de idade, isto é, em lactentes, crianças de 6 a 12 anos e idosos; e, outra via, ocorre com maior frequência em asmáticos em comparação com a população geral.

Reflexos colinérgicos vagais esofagobrônquicos e microaspirações repetidas parecem ser os principais fatores atuantes nessa inter-relação e deve-se atentar para sua presença quando a tosse e/ou broncoespasmo ocorrem ou se intensificam ao decúbito e/ou após refeições, mesmo com o tratamento adequado da asma. Além disso, deve-se lembrar que, nesses casos, as xantinas podem agravar os sintomas por relaxarem o esfíncter esofagiano inferior, agravando o refluxo. ${ }^{1,2,8}$

\section{Micoses broncopulmonares alérgicas}

Constituem um grupo de doenças caracterizadas por hipersensibilidade tipo I (mediada por IgE) e tipo III (mediada por imunocomplexos), que cursam com asma crônica, infiltrados pulmonares transitórios, bronquiectasias proximais, níveis muito elevados de IgE sérica (acima de $1000 \mathrm{UI} / \mathrm{dL}$ ) e necessidade de corticoterapia sistêmica para controle da doença. A primeira enfermidade descrita e a mais frequente é a aspergilose broncopulmonar alérgica (ABPA), mas outros fungos já foram descritos como agentes etiológicos neste grupo de doenças.

$\mathrm{Na} \mathrm{ABPA}$, os esporos fúngicos aderidos às paredes brônquicas e bronquiolares perpetuam uma resposta inflamatória local mediada por IgE e IgG. Esta última, por ativação do sistema do complemento e atração de neutrófilos, causa maior dano à via aérea que na asma alérgica habitual. $^{21,22}$ 


\section{Obesidade}

A asma e a obesidade são condições que representam problemas de saúde pública, sendo a obesidade atualmente considerada fator de risco para a asma. Vários estudos demonstraram a relação entre o percentual do índice de massa corporal (IMC) e a asma. ${ }^{23}$ Um estudo brasileiro de 2011 evidenciou a associação entre obesidade e asma não controlada. ${ }^{24} \mathrm{~A}$ obesidade duplica o risco de asma na idade escolar, e um trabalho que analisou 32.321 crianças asmáticas demonstrou que as com sobrepeso e obesas utilizam mais agonistas beta-adrenérgicos e corticosteroides orais do que pacientes com peso normal. ${ }^{25}$

Mudanças na mecânica respiratória com diminuição da capacidade residual funcional e do volume corrente secundárias à obesidade podem ocasionar piora dos sintomas de asma. A obesidade também aumenta o risco de refluxo gastroesofágico, que atua favorecendo a hiper-responsividade das vias aéreas nos asmáticos. ${ }^{26}$

O tecido adiposo produz inúmeras citocinas, como o fator de necrose tumoral alfa (TNF- $\alpha$ ), a interleucina 6 (IL6), adiponectina e resistina, que têm papel importante na modulação do metabolismo local e sistêmico. A produção de TNF-a é marcadamente aumentada no tecido adiposo de indivíduos obesos e níveis elevados de TNF- $\alpha$ são encontrados também na asma e estão associados à produção de citocinas de perfil Th2 (IL-4 e IL-6) no epitélio brônquico.

Vários estudos transversais demonstraram uma associação significativa entre o índice de massa corporal (IMC) e asma em mulheres, mas não em homens. Uma hipótese plausível é que os hormônios sexuais femininos desempenham um papel importante na etiologia da asma e que esses hormônios são influenciados pela obesidade. A progesterona aumenta a expressão dos receptores beta-2. Outra hipótese é que a obesidade reduziria os níveis de progesterona, reduzindo também a função destes receptores, o que, por sua vez, diminuiria o relaxamento do músculo liso brônquico. ${ }^{27}$

\section{Referências}

1. ASBAI, SBP, SBPT. Stirbulov R, Bernd LAG, Solé D. (editores). IV Diretrizes Brasileiras no Manejo da Asma. Rev Bras Alergia Imunopatol. 2006;29(5):222-45.

2. Global initiative for Asthma (GINA) [Internet]. Bethesda: NHLBI/WHO; 2011. [atualizada em 2011 Dec; acesso em 2012 Feb 26]. Disponível em: http://www.ginasthma.com.

3. Dykewicz MS. Occupational asthma: Current concepts in pathogenesis, diagnosis, and management. J Allergy Clin Immunol. 2009;123(3):519-28.

4. Vercelli D. Discovering susceptibility genes for asthma and allergy. Nature Reviews Immunol. 2008;8:169-82.

5. Duijts L. Fetal and infant origins of asthma. Eur J Epidemiol. 2012 Jan;27(1):5-14.

6. Goplen N, Karim Z, Guo L, et al. ERK1 is important for Th2 differentiantion and development of experimental asthma. FASEB J. 2012. May;26(5):1934-45.

7. Lemanske RF, Busse WW. Asthma: clinical expression and molecular mechanisms. J Allergy Clin Immunol.2010;125:S95-102.

8. Moore WC, Pascual RM. Update in asthma 2009. Am J Respir Crit Care Med. 2010;181:1181-7.

9. Robinson DS. The role of regulatory $\mathrm{T}$ lymphocytes in asthma pathogenesis. Curr Allergy Asthma Rep. 2005;5:136-41.

10. Robinson DS. Regulatory T cells and asthma. Clin Exp Allergy. 2009;39:1314-23.

11. Koh YI, Shim JU, Wi J, et al. The Role of Natural Killer T Cells in the Pathogenesis of Acute Exacerbation of Human Asthma Int Arch Allergy Immunol. 2012;158(2):131-41.

12. Costa E. Asma e Infecção. In: Magalhães Rios JB \& Carvalho LP, eds. Alergia Clínica: Diagnóstico e Tratamento. $2^{-a}$ edição. Rio de Janeiro: Revinter; 2007; p.189-94.

13. Jackson DJ, Sykes A, Mallia P, et al. Asthma exacerbations: origin, effect, and prevention. J Allergy Clin Immunol. 2011;128(6):1165-74.

14. Lucas SR, Platts-Mills TAE. Physical activity and exercise in asthma: Relevance to etiology and treatment. J Allergy Clin Immunol. 2005; 115: 928-34.

15. Carlsen KH, Anderson SD, Bjermer L, et al. Exercise-induced asthma, respiratory and allergic disorders in elite athletes: epidemiology, mechanisms and diagnosis: Part I of the report from the Joint Task Force of the European Respiratory Society (ERS) and the European 
Academy of Allergy and Clinical Immunology (EAACI) in cooperation with GA2LEN. Allergy. 2008;63:387-403.

16. Dortas Jr SD, Pires GV. Asma induzida pela aspirina. Rev Bras Alerg Imunopatol. 2006;29(4):161-66.

17. Bousquet J, Khaltaev N, Cruz AA, et al. Allergic rhinitis and its impact on asthma (ARIA): 2008 Update. Allergy. 2008:63 (Supp. 86):8-160.

18. Togias A. Rhinitis and asthma: Evidence for respiratory system integration. J Allergy Clin Immunol. 2003;111:1171-83.

19. Brausntahl G. The unified immune system: Respiratory tract- nasobronchial interaction mechanisms in allergic airway disease. J Allergy Clin Immunol. 2005;115:142-8.

20. Han DH, Kim SW, Cho SH et al. Predictors of bronchial hyperresponsiveness in chronic rhinosinusitis with nasal polyp. Allergy. 2009;64(1):118-22.

21. Valle SOR, França AT. Aspergilose broncopulmonar alérgica: panorama atual. In: Costa E. Alergia Respiratória. Revista HUPE. 2008;7(2):62-71.
22. Greenberger PA. Allergic bronchopulmonary aspergillosis. In: Grammer LC \& Greenberger PA. eds. Pattersosn's Allergic Diseases. 7th ed. Baltimore: Lippincot, Williams \& Wilkins; 2009. p.439-56.

23. Hong SJ, Lee MS, Lee SY, et al. High body mass index and dietary pattern are associated with childhood asthma. Pediatric Pneumology. 2006 Dec;41(12):1118-24.

24. Barros LL, Souza-Machado A, Corrêa LB, et al. Obesity and poor asthma control in patients with severe asthma. Asthma. 2011 Mar;48(2):171-6.

25. Quinto KB, Zuraw BL, Poon KY, et al. The association of obesity and asthma severity and control in children. J Allergy Clin Immunol. 2011 Nov;128(5):964-9.

26. Shore SA, Fredberg JJ. Obesity, smooth muscle, and airway hyperresponsiveness. J Allergy Clin Immunol. 2005;115(5):925-7.

27. Kryštofová J, Jeseňák M, Bánovčin P. Bronchial asthma and obesity in childhood. Acta Medica (Hradec Králové). 2011;54(3):102-106. 


\section{Autores}

\begin{abstract}
Abdiel Rolim
Programa de Residência Médica e Pós-graduação em Radiologia. Hospital Universitário Pedro Ernesto. Universidade do Estado do Rio de Janeiro. Rio de Janeiro, RJ, Brasil.
\end{abstract}

\section{Adalgisa I. M. Bromerschenckel}

Programa de Pós-graduação Stricto Sensu em Ciências Médicas. Faculdade de Ciências Médicas. Universidade do Estado do Rio de Janeiro. Rio de Janeiro, RJ, Brasil.

\section{Agnaldo José Lopes}

Disciplina de Pneumologia e Tisiologia. Departamento de Especialidades Médicas. Faculdade de Ciências Médicas. Universidade do Estado do Rio de Janeiro. Rio de Janeiro, RJ, Brasil.

\section{Ana Paula V. Soares}

Serviço de Pneumologia e Tisiologia. Policlínica Piquet Carneiro. Universidade do Estado do Rio de Janeiro. Rio de Janeiro, RJ, Brasil.

\section{Anamelia C. Faria}

Serviço de Pneumologia e Tisiologia. Hospital Universitário Pedro Ernesto. Universidade do Estado do Rio de Janeiro. Rio de Janeiro, RJ, Brasil.

\section{Domenico Capone}

Disciplina de Pneumologia e Tisiologia. Departamento de Especialidades Médicas. Faculdade de Ciências Médicas. Universidade do Estado do Rio de Janeiro. Rio de Janeiro, RJ, Brasil.

\section{Eduardo Costa F. Silva}

Serviço de Alergia e Imunologia. Departamento de Medicina Interna. Hospital Universitário Pedro Ernesto. Universidade do Estado do Rio de Janeiro. Rio de Janeiro, RJ, Brasil.

\section{Elizabeth J. C. Bessa}

Disciplina de Pneumologia e Tisiologia. Faculdade de Ciências Médicas. Universidade do Estado do Rio de Janeiro. Rio de Janeiro, RJ, Brasil.

\section{Gabriela A. C. Dias}

Serviço de Alergia e Imunologia. Departamento de Medicina Interna. Hospital Universitário Pedro Ernesto. Universidade do Estado do Rio de Janeiro. Rio de Janeiro, RJ, Brasil.

\section{Jorge Eduardo Pio}

Disciplina de Pneumologia e Tisiologia. Faculdade de Ciências Médicas. Universidade do Estado do Rio de Janeiro. Rio de Janeiro, RJ, Brasil.

\section{Kênia M. da Silva}

Programa de Pós-graduação Stricto Sensu em Ciências Médicas. Faculdade de Ciências Médicas. Universidade do Estado do Rio de Janeiro. Rio de Janeiro, RJ, Brasil.

\section{Leonardo P. Bruno}

Serviço de Pneumologia e Tisiologia. Hospital Universitário Pedro Ernesto. Universidade do Estado do Rio de Janeiro. Rio de Janeiro, RJ, Brasil.

\section{Lívia I. de O. Souza}

Faculdade de Ciências Médicas. Universidade do Estado do Rio de Janeiro. Rio de Janeiro, RJ, Brasil.

\section{Mateus Bettencourt}

Programa de Pós-graduação Stricto Sensu em Ciências Médicas. Faculdade de Ciências Médicas. Universidade do Estado do Rio de Janeiro. Rio de Janeiro, RJ, Brasil.

\section{Paulo Roberto Chauvet}

Disciplina de Pneumologia e Tisiologia. Faculdade de Ciências Médicas. Universidade do Estado do Rio de Janeiro. Rio de Janeiro, RJ, Brasil. 


\section{Rafael Capone}

Programa de Residência Médica e Pós-graduação em Radiologia. Hospital Universitário Pedro Ernesto. Universidade do Estado do Rio de Janeiro. Rio de Janeiro, RJ, Brasil.

\section{Renato Azambuja}

Serviço de Pneumologia e Tisiologia. Hospital Universitário Pedro Ernesto. Universidade do Estado do Rio de Janeiro. Rio de Janeiro, RJ, Brasil.

\section{Rogério M. Bártholo}

Programa de Pós-graduação Stricto Sensu em Ciências Médicas. Faculdade de Ciências Médicas. Universidade do Estado do Rio de Janeiro. Rio de Janeiro, RJ, Brasil.

\section{Sérgio da Cunha}

Disciplina de Tratamento Intensivo. Departamento de Clínica Médica. Faculdade de Ciências Médicas. Universidade do Estado do Rio de Janeiro. Rio de Janeiro, RJ, Brasil.

\section{Thiago P. Bártholo}

Serviço de Pneumologia e Tisiologia. Hospital Universitário Pedro Ernesto. Universidade do Estado do Rio de Janeiro. Rio de Janeiro, RJ, Brasil.

\section{Verônica S. Câmara}

Serviço de Pneumologia e Tisiologia. Policlínica Piquet Carneiro. Universidade do Estado do Rio de Janeiro. Rio de Janeiro, RJ, Brasil. 